\title{
Efeitos antioxidantes do selênio e seu elo com a inflamação e síndrome metabólica
}

\author{
Selenium antioxidant effects and its link with \\ inflammation and metabolic syndrome
}

\author{
Ana Carolina Pinheiro VOLP ${ }^{1}$ \\ Josefina BRESSAN² \\ Helen Hermana Miranda HERMSDORFF ${ }^{3}$ \\ María Ángeles ZULET ${ }^{3}$ \\ José Alfredo MARTíNEZ3
}

\section{R E S U M O}

O estado inflamatório crônico e de baixo grau bem como o estresse oxidativo associados à síndrome metabólica são fatores de risco relevantes para o desenvolvimento de doenças cardiovasculares. Neste contexto, o selênio é um mineral essencial que se encontra associado com o correto funcionamento dos principais processos metabólicos celulares. Estudos in vitro e in vivo em modelos experimentais de síndrome metabólica, bem como em humanos, tem investigado o efeito do selênio sobre a expressão e secreção de biomarcadores de inflamação e de estresse oxidativo. Para obtenção dos artigos sobre efeitos antioxidantes do selênio foram feitas pesquisas nos websites científicos. Na literatura encontramos numerosos artigos sobre os diferentes parâmetros modulados pelas concentrações plasmáticas de selênio, incluindo a proteína- $C$ reativa, a interleucina- 6 , o fator de necrose tumoral- $\alpha$, a interleucina- $1 \beta$ e a proteína transportadora de retinol-4. Esta revisão teve por objetivo discutir o papel do selênio nos processos inflamatórios e de estresse oxidativo, associados à síndrome metabólica.

Termos de indexação: Citocinas. Estresse oxidativo. Inflamação. Resistência à insulina. Selênio. Síndrome metabólica.

\section{A B S T R A C T}

The mild chronic inflammation and oxidative stress associated with metabolic syndrome are relevant risk factors for the development of cardiovascular diseases. In this context, selenium is an essential mineral associated with the correct functioning of the main metabolic processes of the cell. In vitro and in vivo studies in experimental metabolic syndrome models as well as in humans have investigated the effect of selenium on the expression and secretion of inflammation and oxidative stress biomarkers. Articles on the antioxidant effects of selenium

\footnotetext{
$\overline{1}$ Universidade Federal de Ouro Preto, Departamento de Nutrição Clínica e Social. Ouro Preto, MG, Brasil.

2 Universidade Federal de Viçosa, Departamento de Nutrição e Saúde. Av. P.H. Rolfs, s/n., Campus Universitário, $36571-000$ Viçosa, MG, Brasil. Correspondência para/Correspondence to: J. BRESSAN. E-mail: <jbrm@ufv.br>

3 Universidad de Navarra, Departamento de Ciencias de la Alimentación, Fisiología y Toxicología. Pamplona, Navarra, España.
} 
were sought in scientific websites. There are a great number of studies in the literature on the different parameters modulated by blood selenium levels, such as C-reactive protein, interleukin-6, tumor necrosis factor-alpha, interleukin-1 beta and retinol binding protein 4 . The objective of this review is to discuss the role of selenium in inflammatory and oxidative stress processes associated with the metabolic syndrome.

Indexing terms: Cytokines. Oxidative stress. Inflammation. Insulin resistance. Selenium. Metabolic syndrome.

\section{N T R O D U Ç Ã O}

A Síndrome Metabólica (SM) está associada a uma série de fatores de risco que predispõem ao desenvolvimento de doenças cardiovasculares que incluem infarto, acidentes isquêmicos e doença vascular periférica, e desenvolvimento do diabetes do tipo $2^{1,2}$. Os critérios de diagnóstico para a SM são a obesidade abdominal/visceral, as dislipidemias aterogênicas, hipertensão arterial sistêmica e hiperglicemia. Indivíduos com estas manifestações clínicas comumente apresentam um estado protrombótico e pró-inflamatório, caracterizado por uma condição inflamatória subclínica².

O possível elo entre a síndrome metabólica e a inflamação é a Resistência Insulínica (RI). Em outras palavras, a relação entre esta e inflamação pode possuir como causa central defeitos na ação da insulina nos tecidos-alvos (músculo, fígado e tecido adiposo), sendo que estes levam ao aumento do processo inflamatório crônico e de baixo grau. Independentemente do agente iniciante essa relação entre RI e o processo inflamatório é sempre bidirecional ${ }^{3}$. Numerosos estudos têm demonstrado que as doenças crônicas geralmente são acompanhadas ou são consequência do desenvolvimento prévio de processos inflamatórios $^{1,3-6}$. No entanto, a dieta está claramente envolvida na modulação da inflamação, RI e estado oxidativo?.

O selênio é um mineral (oligoelemento) relacionado com a proteção, frente ao dano causado pelo estresse oxidativo, e propõe-se que sua ingestão reduza o risco de doenças crônicas resultantes do estado oxidativo e inflamatório alterado e associado à SM. A literatura científica tem demonstrado que várias categorias de antioxidantes da dieta, dentre eles o selênio, podem ser efetivos em suprimir a ativação de vias pró-inflamatórias, por meio da quelação das molé- culas de radicais livres ${ }^{8}$. Esses nutrientes essenciais bloqueiam a ativação do fator de transcrição Nuclear Kappa-beta (NF- $\kappa \beta$ ), um regulador sensível a oxidantes que modula a produção de mediadores inflamatórios e de moléculas de adesão

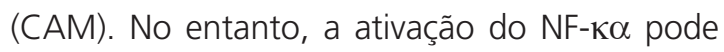
ser também decorrente de situações decorrentes de uma baixa ingestão de antioxidantes. Desta forma, o selênio pode exercer um papel fundamental em minimizar o desenvolvimento de doenças crônicas por reduzir a atividade pró-inflamatória e por favorecer o sistema antioxidante de defesa ${ }^{8}$. Neste sentido, foi demonstrado que o uso de suplemento com propriedades antioxidantes reverteu o aumento de citocinas pró-inflamatórias como a Interleucina-6 (IL-6) e o Fator de Necrose Tumoral- $\alpha$ (TNF- $\alpha$ ), induzido pelo consumo de uma refeição hiperlipídica com predomínio de ácidos graxos saturados ${ }^{9}$.

Uma das funções biológicas mais importantes do selênio é de funcionar como constituinte da Glutatião Peroxidase (GPx), enzima antioxidante que decompõe peróxidos lipídicos e inorgânicos ${ }^{10-12}$. Concentrações baixas de selênio foram associadas à ocorrência de aterosclerose e hiperhomocisteinemia ${ }^{13}$. Em estudo de observação de cinco anos em aproximadamente 1100 homens, com idades entre 55 e 74 anos, baixas concentrações séricas de selênio (menores de $45 \mu \mathrm{g} / \mathrm{L}$ ) foram associadas a mortes por doença cardiovascular e por acidente vascular cerebral ${ }^{14}$.

Dada a relevância clínica e de saúde pública da síndrome metabólica e a demonstração recente de associações entre o selênio e os marcadores inflamatórios e de estresse oxidativo, que constituem fatores de risco no seu desenvolvimento, o objetivo dessa revisão foi integrar e discutir às possíveis interações do selênio com esta síndrome, bem como seu papel na inflamação e estado oxidativo. 


\section{M É T O D O S}

Este estudo consiste em revisão bibliográfica de artigos contendo estudos nacionais e internacionais que relacionam os efeitos do selênio na inflamação e síndrome metabólica. A presente revisão bibliográfica da literatura foi realizada a partir dos periódicos disponíveis no portal da Coordenação de Aperfeiçoamento de Pessoal de Nível Superior (CAPES) e nas principais bases de dados em saúde: MedLine, Lilacs, PubMed e SciELO, utilizando as palavras-chave selenium, oxidative state, inflammation, cytokines, insulin resistance, metabolic syndrome. A sistematização utilizada incluiu a análise e interpretação de material que contivesse "selenium" mais qualquer uma das palavras chaves. O período considerado para inclusão dos artigos levantados foi de 1985 a 2008. Todos os trabalhos que continham o efeito do selênio nos biomarcadores do estado oxidativo e inflamatório foram revisados, sendo que somente estudos com PCR, a IL-6, o TNF- $\alpha$, a interleucina-1 $\beta$ (IL-1 $\beta$ ) e a proteína transportadora de retinol-4 (RBP-4) foram encontrados, independente do efeito ser positivo, negativo ou nulo.

\section{Selênio e biomarcadores}

A reação de inflamação induzida pelos fatores de risco pró-oxidativos e a resposta imunológica associada são os principais eventos que conduzem ao processo de aterogênese conjuntamente com a SM ${ }^{15,16}$. Dentre os biomarcadores de inflamação e estado oxidativo que se encontram descritos na literatura, sobre os quais o selênio exerce seu efeito protetor, estão a $P C R$, a IL-6, o TNF- $\alpha$, a IL-1 $\beta$ e a RBP-4 (Figura 1).

\section{Proteína $\mathrm{C}$ reativa}

A Proteína C Reativa ( $P C R$ ) é uma proteína de fase aguda, sintetizada pelo fígado, adipócitos, tecido endotelial vascular, que tem sua expressão/ secreção regulada por citocinas, predominantemente a IL-6, TNF- $\alpha$ e IL-14,17-18. A PCR é considerada um biomarcador do processo inflamatório e oxidativo, e está envolvida na patogênese da aterosclerose por: a) inibir a transcrição da enzima sintase do óxido nítrico endotelial (eNOS) nas células endoteliais e desestabilizar o RNAm da

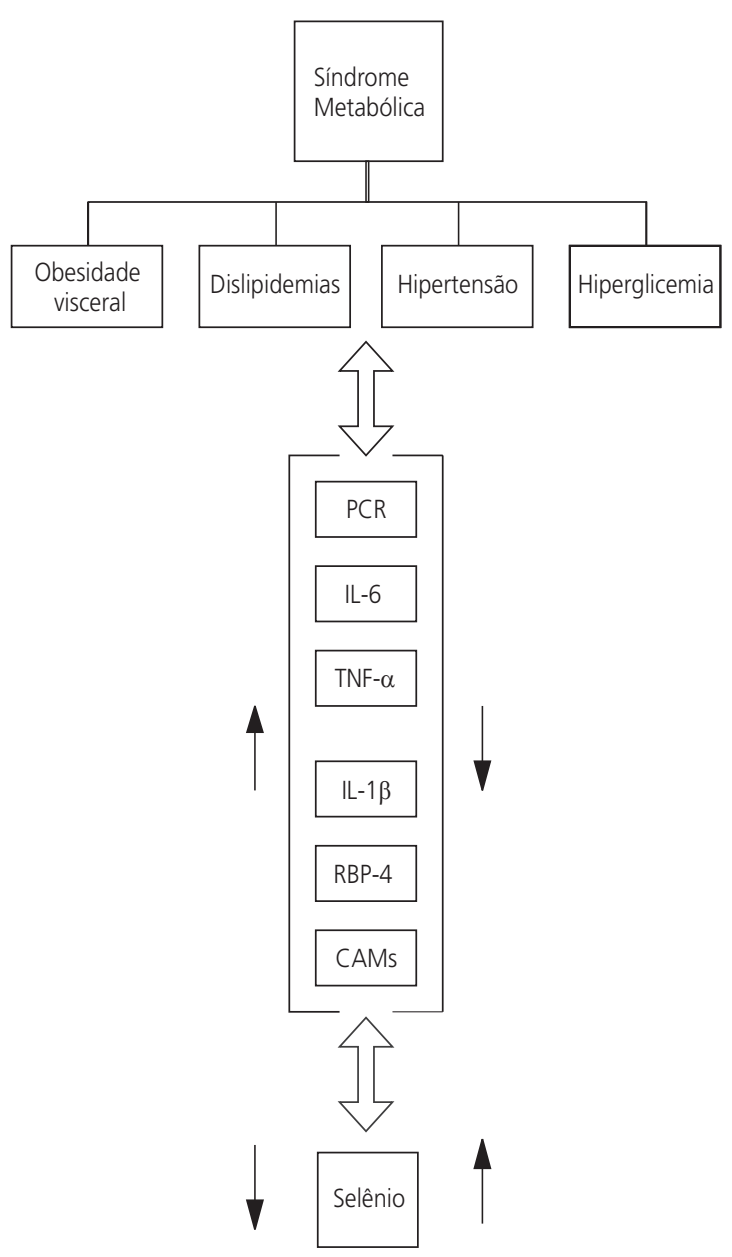

Figura 1. Visão esquemática da relação entre os componentes da síndrome metabólica e biomarcadores de inflamação e estresse oxidativo, bem como do papel protetor do selênio frente à síndrome.

Nota: ingestão adequada do antioxidante selênio exerce seu efeito protetor por diminuir a expressão e a atividade da PCR, IL-6, TNF- $\alpha$, IL-1 $\beta$, RBP-4 e das CAMs. Por outro lado, concentrações elevadas de biomarcadores originados do estresse oxidativo acentuado, pode depletar as reservas de selênio corporais, pelo aumento da demanda metabólica.

PCR: proteína C reativa; IL-6: interleucina-6; TNF- $\alpha$ : fator de necrose tumoral- $\alpha$; IL-1 $\beta$ : interleucina- $1 \beta$; RBP-4: proteína transportadora de retinol- 4; CAM: moléculas de adesão. 
eNOS, o qual leva a um decréscimo na liberação basal de Óxido Nítrico (ON); b) promover a expressão de CAM pelas células endoteliais, induz a Proteína Quimiotáxica de Monócitos-1 (MCP-1) e promover a captação de colesterol pelos macrófagos $^{4}$; c) estimular os monócitos a produzir o fator tissular e citocinas pró-inflamatórias (IL-6 e TNF- $\alpha$ ) por meio da estimulação do NF- $\kappa \beta^{3,4}$.

Pessoas com SM apresentam concentrações plasmáticas de PCR significantemente maiores que pessoas sem SM. Neste estudo, foi demonstrado que ao usar o primeiro tercil (T1) da PCR como referência, a odds ratio da PCR para a SM foi significantemente maior para o segundo tercil (T2: OR= 2,9 [1,5-5,9]) e terceiro tercil (T3: $\mathrm{OR}=5,7[3,1-11,0])^{19}$. Em estudo com pessoas saudáveis foi demonstrado que a concentração sérica de PCR se associou com todos os componentes da SM: glicemia de jejum, circunferência da cintura, triglicerídeos, Lipoproteína de Alta Densidade (HDL-colesterol), pressão arterial sistólica e diastólica, e também com valores de Índice de Massa Corporal (IMC), insulina, Índice de Sensibilidade à Insulina $\left(\mathrm{S}_{1}\right)$, colesterol total e Lipoproteína de Baixa Densidade (LDL-colesterol). Houve um aumento linear nas concentrações de PCR com o aumento do número de desordens metabólicas (dislipidemia, adiposidade central, RI e hipertensão). Desta forma, a inflamação crônica subclínica faz parte da SM, porém a PCR é um preditor de eventos cardiovasculares, independentemente de estar relacionada à sensibilidade insulínica ${ }^{6}$. Por outro lado, o decréscimo na sensibilidade à insulina pode levar a um aumento da expressão de PCR pela contra-regulação dos efeitos fisiológicos da insulina (efeitos antiinflamatórios) na síntese hepática de proteínas de fase aguda ${ }^{3}$.

Com o objetivo de avaliar a associação entre a PCR e o selênio, um grupo de pesquisadores analisou dados de 14364 participantes do National Health and Nutrition Examination Survey III (1988-1994) ${ }^{20}$. Nesse estudo, as concentrações de PCR foram inversas e significativamente associadas com o selênio, de maneira independente da idade, sexo, etnia, educação, IMC, atividade física de lazer e uso de aspirina. Quando comparado o maior quartil (Q4) das concentrações de PCR com o menor quartil (Q1), uma associação inversa foi notada entre $P C R$ e selênio. De fato, a inflamação pode diminuir as concentrações de antioxidantes por estes neutralizarem os Radicais Superóxidos (ROS) produzidos durante o mesmo processo inflamatório. Os ROS e a peroxidação lipídica podem promover a produção de citocinas pró-inflamatórias (PCR). Assim, neutralizando o excesso de ROS, bem como a peroxidação lipídica, poderia ser reduzido o estímulo necessário para evitar a ativação da cascata de citocinas pró-iflamatórias ${ }^{20}$.

\section{Interleucina-6}

A IL-6 é uma citocina pleiotrópica que desempenha uma série de funções nos processos imunes celulares e humorais relacionados à inflamação, defesa do hospedeiro e lesão tecidual ${ }^{4}$. A mesma é mediadora central da resposta de fase aguda e a principal citocina pró-coagulante, pois determina a produção e elevação das concentrações plasmáticas estimuladas pelo fígado de fibrinogênio, proteína amilóide A (SAA), e em especial, da PCR ${ }^{4,15,21}$. Indivíduos com concentrações aumentadas de PCR $(>1,35 \mu \mathrm{g} / \mathrm{mL})$ apresentavam valores aumentados de IL-6 $(3,22 \mathrm{pg} / \mathrm{mL})$, quando comparados com indivíduos com concentrações baixas de PCR $(<1,35 \mu \mathrm{g} / \mathrm{mL})$ que apresentavam valores baixos de IL-6 $(1,35 \mathrm{ng} / \mathrm{mL})^{21}$.

A IL-6 é produzida e secretada por células endoteliais, células musculares lisas, monócitos, macrófagos e tecido adiposo, e pode contribuir no desenvolvimento da lesão aterosclerótica pelo seu efeito parácrino, autócrino e endócrino ${ }^{4}$. No tecido adiposo, é secretada principalmente pelo tecido adiposo visceral. A IL-6 é uma citocina pró-inflamatória, envolvida no processo de desenvolvimento da hiperinsulinemia e SM, pois desempenha papel importante no metabolismo de carboidratos e lipídeos por aumentar a lipólise, com inibição da Lipase Lipoproteica (LPL) e aumento da liberação de ácidos graxos livres e glicerol, e 
redução da expressão do substrato do receptor de insulina-1 (IRS-1) e GLUT-4 nos tecidos muscular e adiposo ${ }^{18}$.

Um estudo demonstrou que, em pessoas saudáveis, a IL-6 correlaciona-se com todos os componentes da SM (glicemia, circunferência da cintura, concentrações séricas de triglicerídeos e de HDL-colesterol, pressão sistólica, pressão diastólica), além da concentração sérica de insulina, IMC e os marcadores inflamatórios IL-18 e PCR ${ }^{5}$. Nesse estudo, quanto maior o número de componentes da SM apresentados pelos indivíduos $(0,1,2$ e $\geq 3)$, maiores foram os valores da IL-6 $(3,08[2,92-3,26] ; 3,47[3,31-3,65] ; 3,93[3,71-4,15]$; 4,33 [4,05-4,61] $\mu \mathrm{g} / \mathrm{L})$, respectivamente. Por fim, em análise multivariada, indivíduos que apresentavam valores de IL-6 no maior tercil $(>3,90 \mu \mathrm{g} / \mathrm{L})$ tinham maior risco para a SM após ajustado para sexo e idade (T3: OR= 2,58[1,60-4,16]; 95\%) e após ajustado para sexo, idade e insulina (somente para indivíduos com IMC $\left.<30 \mathrm{~kg} / \mathrm{m}^{2}\right)(\mathrm{Q} 3: \mathrm{OR}=2,03$ $[1,06-3,88] ; 95 \%)$, quando comparados aos indivíduos com valores de IL-6 no menor tercil $(<2,90 \mu \mathrm{g} / \mathrm{L})^{22}$. Desta forma, concentrações elevadas de IL-6 estão associadas com a SM de uma forma dependente da obesidade.

Concentrações elevadas de IL-6 têm sido relacionadas com um prognóstico ruim de saúde ${ }^{23,24}$. Desta forma, pesquisadores estudam o papel dos antioxidantes da dieta em relação às concentrações plasmáticas desta citocina. Em um estudo, foi verificado que o selênio da dieta pode suprimir a concentração plasmática de IL-6, por desempenhar um papel importante no decréscimo do estado oxidativo e da resposta inflamatória8. Nesse estudo, indivíduos que possuíam maiores concentrações séricas de selênio, eram menos propensos a apresentar maiores concentrações séricas de IL-6 (>4,81 pg/mL) (T3: OR=0,65 [0,52-0,80]; 95\%). Exceção se fazia aos indivíduos que apresentavam maiores concentrações séricas de zinco (T3: OR=0,99 [0,82-1,20]; 95\%). Os autores discutem que, de fato, o selênio é um constituinte da GPx, a enzima com maior ação redutora de peróxido de hidrogênio e de peróxidos de lipídeos ${ }^{8,25}$.
O zinco forma parte da enzima antioxidante citosólica, Cobre-Zinco Superóxido Dismutase (CuZn-SOD) 8,26. Moléculas de superóxido são convertidas a peróxido de hidrogênio pela CuZn-SOD, a qual ativa as vias inflamatórias ${ }^{8,27}$. Uma maior atividade da CuZn-SOD em relação a GPx dependente de selênio está relacionada com o aumento da peroxidação lipídica e ativação do $\mathrm{NF}-\kappa \beta$, através do aumento de peróxido de hidrogênio ${ }^{8,28,29}$. Embora nesse estudo não tenha sido encontrada relação entre as concentrações séricas de zinco e IL-6, os autores sugeriram que o processo oxidativo ocorrido pelo aumento de peróxido de hidrogênio e peróxidos de lipídeos, quando comparado aos radicais superóxido pode, em parte, ter estimulado a geração de IL-68,30. Por fim, aqueles que possuíam as concentrações de selênio no tercil mais baixo apresentavam um alto risco de mortalidade total durante um período de cinco anos (T1: RR=1,54 [1,03-2,32]; 95\%).

\section{Fator de necrose tumoral- $\alpha$}

O Fator de Necrose Tumoral- $\alpha$ (TNF- $\alpha$ ) é uma citocina com ação parácrina e endócrina ${ }^{31,32}$. É secretado por adipócitos, macrófagos, células musculares lisas e esqueléticas e células endoteliais ${ }^{4,33}$ e está envolvido no processo de inflamação crônica e de baixo grau, pois desempenha um papel modulador na expressão e secreção de outras citocinas ${ }^{4}$. Assim como a IL-6, o TNF- $\alpha$ é mediador central da resposta de fase aguda, pois também modula a produção hepática de fibrinogênio, SAA, inibidor de plasminogênio ativado-1 (PAI-1) e em especial, da PCR e, consequentemente eleva as concentrações plasmáticas dessas proteínas ${ }^{4,15,21}$. Ainda, esta citocina é um potente estimulador da expressão das moléculas de adesão: molécula de adesão intercelular-1 (ICAM-1), molécula de adesão celular vascular-1 (VCAM-1) e da E-seletina ${ }^{34}$.

No tecido adiposo, o TNF- $\alpha$ induz a expressão de IL-6 e atua no metabolismo lipídico e glicídico ${ }^{32,35,36}$. Neste sentido, o TNF- $\alpha$ desempenha 
um papel regulador no acúmulo de gordura corporal, através da inibição da lipogênese, com diminuição da expressão da (LPL), do GLUT-4 e da acetil-CoA sintetase, bem como aumento da lipólise ${ }^{32,36}$. Em indivíduos obesos há uma correlação inversa e significante entre TNF- $\alpha$ e metabolismo da glicose ${ }^{35}$. Este efeito ocorre devido à supressão pelo TNF- $\alpha$ da sinalização da insulina, reduzindo a fosforilação do IRS-1 e a atividade do receptor insulina quinase (PI3K). Tal fato resulta em redução da síntese e translocação do transportador de glicose (GLUT-4) para a membrana com consequente diminuição na captação de glicose pelas células mediada pela ação da insulina. Por sua vez, esta redução da sensibilidade periférica à insulina ocasiona o aumento da glicogênese hepática e reduz o clearance de glicose pelo músculo esquelético e tecido adiposo, caracterizando um quadro de hiperinsulinemia ${ }^{36,37}$. A expressão de RNAm e a secreção de TNF- $\alpha$ são elevadas em obesos, correlacionando-se positivamente com o aumento do volume dos adipócitos tanto no depósito visceral quanto subcutâneo ${ }^{32,38}$. Desta forma, sua expressão no tecido adiposo tem sido implicada como o fator causal na patogênese da obesidade ligada a R/4,33.

Também se têm observado correlações positivas e significantes entre TNF- $\alpha$ e os componentes da SM: triglicerídeos, HDL-colesterol e pressão arterial sistólica, além de uma relação positiva das concentrações de TNF- $\alpha$ com o IMC, a sensibilidade à insulina e a concentração circulante de PAI-121. Visto que o TNF- $\alpha$ está associado com os componentes da $\mathrm{SM}^{21}$, o mesmo pode predizer risco para doenças cardiovasculares e infarto ${ }^{4,39}$. Em estudo com análise univariada, concentrações séricas de TNF- $\alpha$ no maior quartil $(11,20 \mathrm{pg} / \mathrm{mL})$ predizia risco de mortalidade/óbito dentro de 24 meses (Q4: RR=3,09 [1,42-6,69]; 95\%) em pacientes com falência cardíaca crônica $(\text { ICC })^{39}$.

Por outro lado, as células endoteliais desempenham um papel principal nas reações imunológicas e as CAM como a P-seletina, a ICAM-1, a VCAM-1 e a molécula de adesão leucocitária endotelial-1 (ELAM-1) são importantes mediadores no recrutamento de leucócitos em inflamações pulmonares ${ }^{40}$. Em pacientes que exibem reação alérgica tardia, foram observadas em seus macrófagos alveolares altas concentrações de IL-6 e TNF- $\alpha$. Desta forma, essas duas citocinas podem estimular a expressão endotelial de CAM que, por sua vez, participam no desenvolvimento da reação inflamatória da asma brônquica ${ }^{38}$. Neste sentido, foi avaliado o efeito de um sobrenadante de macrófagos de pacientes com asma tardia na expressão das moléculas de adesão (ICAM-1 e ELAM-1) por células endoteliais humanas, estimuladas por TNF recombinante humano (TNF-hr) (em doses ótimas de $500 \mathrm{U} / \mathrm{mL}$ ). Os resultados obtidos nesse estudo mostraram que este sobrenadante aumentou significativamente a expressão nas células endoteliais de ICAM-1 e ELAM-1 (respectivamente $90,4 \%$ e $75,2 \%$ ). Ainda, ao neutralizar o efeito do TNF recombinante houve uma diminuição de $68,0 \%$ e $80,0 \%$, respectivamente, na expressão de ICAM-1 e ELAM-1 ${ }^{41}$.

A respeito do efeito do selênio sobre a atividade do TNF- $\alpha$, um estudo in vitro demonstra que o selênio inibe de forma significativa e de maneira dose-dependente a expressão das CAM: ICAM-1, VCAM-1 e E-seletina, por meio da inibição da atividade do TNF- $\alpha$. Ao mesmo tempo, o selênio pôde inibir in vitro a expressão dessas mesmas CAM em situação induzida de hiperglicemia e hiperinsulinemia, demonstrando seu potente e promissor papel frente a situações como a aterosclerose e o diabetes do tipo $2^{41}$.

Outro estudo in vitro também demonstra que o selênio pode modular os mecanismos imunológicos da asma, por regular a expressão das CAM e, consequentemente, o processo de inflamação associado ${ }^{40}$. Asmáticos possuem a expressão estimulada de P-seletina, VCAM-1 e da ELAM-1 em células endoteliais. Após a suplementação com selênio, a expressão destes marcadores inflamatórios em asmáticos estava significativamente maior que em indivíduos saudáveis, enquanto que a produção de ICAM-1 apresentou-se também elevada, mas sem significância. De- 
pois de três meses de suplementação de selênio, os níveis de expressão de VCAM-1 e ELAM-1 estiveram significativamente diminuídos e, depois de seis meses de suplementação, a intensidade da expressão da P-seletina e da ICAM-1 também estavam. Estes resultados foram obtidos de maneira dose-dependente da suplementação de selênio, com uma inibição máxima (80\%) na expressão das CAM para uma dose de $10 \mu \mathrm{g} / \mathrm{mL}$ de selênio in vitro ${ }^{40}$.

\section{Interleucina-1 $\beta$}

A Interleucina-1 $\beta$ (IL-1 $\beta$ ) pertence à grande família das IL-1, que estão envolvidas no processo inflamatório da aterosclerose e SM. É uma citocina pró-inflamatória, produzida principalmente por monócitos e macrófagos, mas também por outras células como as células endoteliais, musculares lisas e plaquetas ativadas. A IL-1 $\beta$ induz a ativação da transcripção do gene NF- $\kappa \beta$ para a expressão das CAM e de citocinas $^{4,42}$. Ainda, promove o aumento da expressão das CAM, facilitando o recrutamento e a agregação de outras células inflamatórias no endotélio ativado ${ }^{4}$.

A IL-1 $\beta$, conjuntamente com o TNF- $\alpha$, estimula a produção de IL- 6 por células musculares lisas e aumenta a expressão de macrófagos, fator de crescimento derivado de plaquetas (PDGF) e fator de crescimento de fibroblastos (FGF), os quais estão associados com a progressão e desencadeamento do processo inflamatório ${ }^{4}$.

O selênio pode desempenhar um importante papel antiinflamatório, pois o mesmo inibe a ativação do NF- $\kappa \beta$ induzido pela IL- $1 \beta^{42}$. De fato, estudos in vitro demonstram que uma superexpressão da enzima GPx, em células endoteliais humanas, inibiu a atividade do NF- $\kappa \beta^{43}$. A modu-

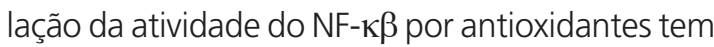
estimulado a pesquisa sobre o efeito de sistemas enzimáticos endógenos na regulação do NF-к $\beta$ (expressão e atividade) in vivo ${ }^{42}$. Em estudo in vitro com uma linhagem de células produtoras de insulina, a superexpressão de Mn SOD reduziu de maneira significativa a ativação do NF- $\kappa \beta$ mediada pela IL-1 $\beta$ e, consequentemente, a indução da óxido nítrico sintetase (iNOS), indicando a relevância dos radicais superóxidos (ROS) derivados de mitocôndria em situação de indução de morte celular promovidas por citocinas. O efeito do MnSOD poderia prevenir a formação de peroxinitrito a partir do $\mathrm{O}_{2}^{-}$e do $\mathrm{NO}$, o qual é muito mais reativo que $\mathrm{o}_{2} \mathrm{O}_{2}$, produto da dismutação do $\mathrm{O}_{2}^{-}$promovida pelo $\mathrm{MnSOD}^{44}$.

\section{Proteína transportadora de retinol-4}

A Retinol Binding Protein-4 (RBP-4) foi identificada como uma nova adipocina a qual está envolvida na modulação do metabolismo da gli$\operatorname{cose}^{45}$. A RPB-4 está envolvida na redução da sensibilidade periférica e hepática à insulina por favorecer a gliconeogênese hepática ${ }^{46}$ através da ativação do fosfoenol piruvato carboxiquinase ${ }^{47}$. Desta forma, tem sido proposto como um elo entre a obesidade e a resistência insulínica, visto que concentrações séricas elevadas de RBP-4 se encontram em obesos com resistência insulínica e diabetes do tipo $2^{45}$.

Em indivíduos não obesos, não diabéticos, com hipercolesterolemia, a concentração sérica de RBP-4 se correlacionou significativamente com a glicemia de jejum e triglicerídeos, independente da idade, sexo e IMC. Por outro lado, não houve relação significativa entre a RBP-4 e a concentração de insulina, HDL-colesterol, LDL-colesterol e valores de HOMA-IR (homeostasis model assessment: modelo de avaliação da homeostase de resistência à insulina). Neste estudo, os valores de RBP-4 foram significativamente associados com a concentração de adiponectina, independente da idade, sexo e $\mathrm{IMC}^{48}$.

Recentemente, um estudo demonstrou que a dieta e o estilo de vida condicionam a concentração plasmática de RBP-4 em uma população jovem. Nesse estudo, a concentração de RBP-4 apresentou uma correlação negativa estatisticamente significativa com a ingestão diária de selênio. Em modelo de regressão linear múltipla, a ingestão de selênio apresentou uma associação 
negativa com a concentração de RBP-4, de forma independente do sexo, ingestão calórica diária e o tempo que fuma ou que fumou ${ }^{49}$. Nenhum estudo até o momento investigou o efeito da suplementação de selênio nas concentrações plasmáticas desta adipocina.

\section{CONSIDERAÇÕ ES FINAIS}

Os resultados discutidos nesta revisão apresentam importância clínica relevante. A aplicação do selênio sobre os diversos componentes da SM (adiposidade, dislipidemia, hipertensão, hiperglicemia) pode apresentar efeitos benéficos tanto na prevenção como no tratamento do diabetes do tipo 2 e das doenças cardiovasculares. Ainda, a inflamação subclínica é de fato uma outra faceta da SM, e as condutas de ação antiinflamatória, como a melhora na sensibilidade à insulina e redução da expressão e secreção dos biomarcadores inflamatórios e das moléculas de adesão podem ser necessárias, incluindo redução de peso, atividade física e controle na alimentação.

O processo infamatório é uma reação muito complexa. Nesta revisão pode-se observar que o selênio ajuda a neutralizar o excesso de ROS, bem como a peroxidação lipídica, e este mecanismo está envolvido na redução do estímulo necessário para evitar a ativação da cascata de citocinas pró-iflamatórias, dentre elas a PCR, sendo sua expressão/secreção regulada por citocinas, predominantemente a IL-6, TNF- $\alpha$ e IL-1. Ao contrário, quando o processo oxidativo advindo pelo aumento de peróxido de hidrogênio e peróxidos de lipídios, podem estimular a geração de IL-6, a qual estimula a produção de PCR. Ainda, pode-se notar o efeito modulador do selênio em estados inflamatórios e imunológicos alterados, como em situações de alergias e asma, por regular a expressão das CAM e, consequentemente, o processo de inflamação associado. Em outras palavras, o selênio exerceu efeito sobre a IL-6 e TNF- $\alpha$ e consequentemente das CAM, pois estas duas citocinas podem estimular a expressão endotelial de CAM que, por sua vez, participam no desenvolvimento da reação inflamatória da asma brônquica. Em relação à RBP-4, a ingestão de selênio apresentou uma associação negativa com suas concentrações, porém até o momento nenhum estudo avaliou o efeito da suplementação de selênio neste biomarcador.

Desta forma, esperam-se mais estudos sobre os efeitos antioxidantes do selênio na inflamação e SM. O efeito do selênio em relação a todos estes biomarcadores mencionados parece desempenhar vários papéis e seguir diversos caminhos metabólicos.

Por fim, algumas questões permanecem por serem esclarecidas. Não está claro quando uma baixa ingestão de selênio na dieta, ou um estado de estresse oxidativo elevado (doenças crônicas, alergias, asma) ou ambos refletem o estado inflamatório de um indivíduo, embora a inflamação apresente algum impacto na concentração sérica de selênio. Mais pesquisas são necessárias para poder elucidar o quanto o selênio pode influenciar nas concentrações dos biomarcadores inflamatórios, tanto em situações de saúde quanto em situações de doença.

\section{A GRADECIMENTOS}

À Coordenação de Aperfeiçoamento de Pessoal de Nível Superior, pela concessão das bolsas de estudos dentro do Projeto referência MECD 109/06 e da bolsa de estudo, modalidade doutorado pleno (Processo n 375605-0). Também ao Departamento de Ciencias de la Alimentación, Fisiología y Toxicología de la Universidad de Navarra - Espanha, por ceder espaço e orientação à pesquisa em nível de cooperação internacional. À Fundação de Amparo à Pesquisa de Minas Gerais.

\section{COLABORADORES}

A.C.P. VOLP e J. BRESSAN participaram da concepção, do planejamento, da análise, da interpretação do material, do delineamento, da redação e da revisão crítica. H.H.M. HERMSDORFF participou da análise e interpretação do material bibliográfico e da revisão crítica. M.A. ZULET e J.A. MARTÍNEZ participaram da concepção e do delineamento do artigo. 


\section{REFERÊ NCIAS}

1. Third Report of the National Cholesterol Education Program (NCEP). Expert panel on detection, evaluation, and treatment of high blood cholesterol in adults (Adult treatment panel III) Final report. Circulation. 2002; 106(25):3143-421.

2. Grundy SM, Cleeman JI, Daniels SR, Donato KA, Eckel RH, Franklin BA, et al. Diagnosis and management of the metabolic syndrome. Circulation. 2005; 112(17):2735-52.

3. Dandona P, Chaudhuri A, Ghanim H, Mohanty P. Proinflammatory effects of glucose and antiinflammatory effects of insulin: relevance to cardiovascular disease. Am J Cardiol. 2007; 99 (Suppl):15B-26B.

4. Francisco G, Hernández C, Simó R. Serum markers of vascular inflammation in dyslipidemia. Clin Chim Acta. 2006; 369(1):1-16.

5. Yudkin JS, Juhan-Vague I, Hawe E, Humphries SE, Di Minno G, Margaglione $M$, et al. The HIFMECH Study Group. Low-grade inflammation may play a role in the etiology of the metabolic syndrome in patients with coronary heart disease: the HIFMECH Study. Metabolism. 2004; 53(7):852-7.

6. Festa A, D'Agostino R, Howard G, Mykkanen L, Tracy RP, Haffner SM. Chronic subclinical inflammation as part of the insulin resistance syndrome. Circulation. 2000; 102(1):42-7.

7. Krauss RM, Eckel RH, Howard B, Appel LI, Daniels SR, Deckelbaum RJ, et al. AHA Dietary Guidelines: revision 2000: a statement for healthcare professionals from the Nutrition Committee of The American Heart Association. Circulation. 2000; 102 (18):2284-99.

8. Walston J, Xue Q, Semba RB, Ferrucci L, Cappola $A R$, Ricks $M$, et al. Serum antioxidants, inflammation, and total mortality in older women. AJE. 2006; 163(1):18-26.

9. Wells BJ, Mainous AG III, Everett CJ. Association between dietary arginine and C-reactive protein. Nutrition. 2005; 21(2):125-30.

10. Sinatra ST, De Marco J. Free radicals, oxidative stress, oxidized low density lipoprotein (LDL) and the heart: antioxidants and other strategies to limit cardiovascular damage. Conn Med. 1995; 59(10): 579-88.

11. Rayman MP. The importance of selenium to human health. Lancet. 2000; 356(15):233-41.

12. Alissa EM, Bahijri SM, Ferns GA. The controversy surrounding selenium and cardiovascular disease: a review of the evidence. Med Sci Monit. 2003; 9(1):9-18.
13. González S, Huerta JM, Álvarez-Uría J, Fernández S, Patterson AM, Laceras C. Serum selenium is associated with plasma homocysteine concentrations in elderly humans. J Nutr. 2004, 134(7):1736-40.

14. Virtamo J, Valkeila E, Alfthan G, Punsar S, Huttunen $\mathrm{JK}$, Karvonen MJ. Serum selenium and the risk of coronary heart disease and stroke. Am J Epidemiol. 1985; 122(2):276-82.

15. Willerson JT, Ridker PM. Inflammation as a cardiovascular risk factor. Circulation. 2004; 109(1): 2-10.

16. Ross R. Atherosclerosis: an inflammatory disease. New Engl J Med. 1999; 340(2):115-26.

17. Abdellaoui A, Al-Khaffaf H. C-reactive protein (CRP) as a marker in peripheral vascular disease. Eur J Vasc Endovasc Surg. 2007; 20(5):1-5.

18. Rexrode KM, Pradhan A, Mansos JE, Buring JE, Ridker PM. Relationship of total and abdominal adiposity with CRP and IL-6 in women. Ann Epidemiol. 2003; 13(10):1-9.

19. Ishikawa S, Kayaba K, Gotoh T, Nakamura Y, Kajii E. Metabolic syndrome and C-reactive protein in the general population - JMS Cohort Study. Circ J. 2007; 71(1):26-31.

20. Ford ES, Liu S, Mannino DM, Giles WH, Smith SJ. $\mathrm{C}$-reactive protein concentration and concentrations of blood vitamins, carotenoids, and selenium among United States adults. Eur J Clin Nutr. 2003; 57(9):1157-63.

21. Yudkin JS, Stehouwer CDA, Emeis JJ, Coppack SW. C-reactive protein in healthy subjects: associations with obesity, insulin resistance, and endotelial dysfunction: a potencial role for cytokines originating from adipose tissue? Arterioscler Thromb Vasc Biol. 1999; 19(4):972-8.

22. Hung J, McQuillan BM, Chapman CML, Thompson PL, Beilby JP. Elevated interleukin-18 levels are associated with the metabolic syndrome independent of obesity and insulin resistance. Arterioscler Thromb Vasc Biol. 2005; 25(6):1268-73.

23. Volpato S, Guralnik JM, Ferrucci P, Balfour J, Chaves $P$, Fried LP, et al. Cardiovascular disease, interleukin6 , and risk of mortality in older women: the Women's Health and Aging Study. Circulation. 2001; 103(7):947-53.

24. Harris TB, Ferrucci L, Tracy RP, Corti MC, Wacholder $\mathrm{S}$, Ettinger WH Jr, et al. Associations of elevated interleukin-6 and C-reactive protein levels with mortality in the elderly. Am J Med. 1999; 106: 506-12.

25. Rayman MP. The importance of selenium to human health. Lancet. 2000; 356(9225):233-41.

26. Klotz LO, Kroncke KD, Buchczyk DP, Sies H. Role of copper, zinc, selenium and tellurium in the cellular 
defense against oxidative and nitrosative stress. J Nutr. 2003; 133(1):1448S-51S.

27. Kunsch C, Medford RM. Oxidative stress as a regulator of gene expression in the vasculature. Circ Res. 1999; 85(8):753-66.

28. de Haan JB, Cristiano F, lannello R, Bladier C, Kelner $\mathrm{MJ}$, Kola I. Elevation in the ratio of $\mathrm{Cu} / \mathrm{Zn}$-superoxide dismutase to glutathione peroxidase activity induces features of cellular senescence and this effect is mediated by hydrogen peroxide. Hum Mol Genet. 1996; 5(2):283-92.

29. de Haan JB, Cristiano F, lannello RC, Kola I. Cu/Znsuperoxide dismutase and glutathione peroxidase during aging. Biochem Mol Biol Int. 1995; 35(6): 1281-97.

30. Zhang J, Johnston G, Stebler B, Keller ET. Hydrogen peroxide activates NF- $\kappa \beta$ and the interleukin- 6 promoter through NF- $\kappa \beta$ inducing kinase. Antioxid Redox Signal. 2001; 3(3):493-504.

31. Ruan $\mathrm{H}$, Lodish HF. Insulin resistance in adipose tissue: direct and indirect effects of tumor necrosis factor-alfa. Cytokine Growth Rev. 2003; 14(5): 447-55.

32. Montague CT, Prins JB, Sanders L, Zhang J, Sewter $C P$, Digby J, et al. Depot: related gene expression in human subcutaneous and omental adipocytes. Diabetes. 1998; 47(9):1384-90.

33. Klein J, Perwitz Z, Kraus D, Fasshauer M. Adipose tissue as source and target for novel therapies. Trends Endocrinol Metab. 2006; 17(1):1-7.

34. Zhang F, Yu W, Hargrove JL, Greenspan P, Dean $R G$, Taylor EW, et al. Inhibition of TNF- $\alpha$ induced ICAM-1, VCAM-1 and E-selectin expression by selenium. Atherosclerosis. 2002; 161(2):381-6.

35. Winkler G, Kiss S, Ketszthelyi L, Sapi Z, Ory I, Salamon $F$, et al. Expression of tumor necrosis factor (TNF-alfa) protein in the subcutaneous and visceral adipose tissue in correlation with adipocyte cell volume, serum TNF-alfa, soluble serum TNF-receptor-2 concentrations and C-peptide level. Eur J Endocrinol. 2003; 149(2):129-35.

36. Arner P. Differences in lipolysis between human subcutaneous and omental adipose tissues. Ann Med. 1995; 27(7):435-8.

37. Hsueh WA, Law R. The central role of fat and effect of peroxisome proliferator-activated and cardiovascular disease. Am J Cardiol. 2003; 92(1): 3-9.

38. Lassalle P, Gosset P, Delneste $Y$, Tsicopoulos A, Capron A, Joseph $M$, et al. Modulation of adhesion molecule expression on endothelial cells during the late asthmatic reaction: role of macrophage-derived tumour necrosis factor-alpha. Clin Exp Immunol. 1993; 94(1):105-10.

39. Rauchhaus M, Doehner W, Francis DP, Davos C, Kemp M, Liebenthal $C$, et al. Plasma cytokine parameters and mortality in patients with chronic heart failure. Circulation. 2000; 102(25): 3060-7.

40. Horváthová M, Jahnová E, Gazdík F. Effect of selenium supplementation in asthmatic subjects on the expression of endothelial cell adhesion molecules in culture. Biol Trace Elem Res. 1999; 69(1):15-26.

41. Zheng HT, Zhou LN, Huang CJ, Hua X, Jian R, Su $\mathrm{BH}$, et al. Selenium inhibits high glucose- and high insulin-induced adhesion molecule expression in vascular endotelial cells. Arch Med Res. 2008; 39(4):373-9.

42. Brigelius-Flohé R, Banning A, Kny M, Bol GF. Redox events in interleukin-1 signaling. Arch Biochem Biophys. 2004; 423(1):66-73.

43. Brigelius-Flohé R, Friedrichs B, Maurer S, Schultz $M$, Streicher R. Interleukin-1 induced nuclear factor $\kappa \beta$ activation is inhibited by overexpression of phospholipid hydroperoxide glutathione peroxidase in a human endothelial cell line. Biochem J. 1997; 328(Pt 1):199-203.

44. Azevedo-Martins AK, Lortz S, Lenzen S, Curi R, Eizirik DL, Tiedge M. Improvement of the mitochondrial antioxidant defense status prevents cytokine-induced nuclear factor-kappa beta activation in insulin-producing cells. Diabetes. 2003; 52(1):93-101.

45. Yang Q, Graham TE, Mody N, Preitner F, Peroni OD, Zabolotny JM, et al. Serum retinol binding protein contributes to insulin resistance in obesity and type 2 diabetes. Nature. 2005; 436(7049): 356-62.

46. Zulet MA, Puchau B, Navarro C, Martí A, Martínez JA. Biomarcadores del estado inflamatorio: Nexo de unión con la obesidad y complicaciones asociadas. Nutr Hosp. 2007; 22(5): 511-27.

47. Craig RL, Chu WS, Elbein SC. Retinol binding protein 4 as a candidate gene for type 2 diabetes and prediabetic intermediate traits. Mol Genet Metab. 2007; 90(3):338-44.

48. Shin MJ, Kang SM, Jang Y, Lee JH, Oh J, Chung JH, et al. Serum retinol binding protein 4 levels are associated with serum adiponectin levels in nondiabetic, non-obese subjects with hypercholesterolemia. Clin Chim Acta. 2007; 378(1-2):227-9.

49. Hermsdorff HHM, Zulet Alzórriz MA, Lecea BP, Bressan J, Martínez Hernández JA. La dieta y el estilo de vida condicionan los niveles de la adipoquina RBP4 en población adulta joven: Posible asociación con el estado oxidativo. Rev Esp Obes. 2007; 5(5):281.

Recebido em: 28/7/2008

Versão final reapresentada em: 13/7/2009 Aprovado em: 31/3/2010 